\title{
El lenguaje malsonante y su traducción: comparación entre los doblajes de filmes anglófonos al italiano y al español
}

\author{
Pablo Zamora \\ Universidad de Murcia. Departamento de Traducción e Interpretación \\ Santo Cristo, 1 \\ 30001 Murcia \\ pabloz@um.es \\ ORCID: 0000-0003-0826-6519
}

\author{
Maria Pavesi \\ Università degli Studi di Pavia. Dipartimento di Studi Umanistici \\ Corso Strada Nuova, 65 \\ 27100 Pavia \\ maria.pavesi@unipv.it \\ ORCID: 0000-0002-7474-9546
}

\section{Resumen}

El léxico soez se emplea en la interacción social y cumple, en la mayor parte de los casos, una función ofensiva. En los largometrajes los vulgarismos sirven esencialmente para dotar a los diálogos fílmicos de una fuerza emotiva y para caracterizar lingüísticamente a los personajes; asimismo, son marcas orales que contribuyen a recrear una lengua que resulte natural y verosímil, que se asemeje en la manera de lo posible al hablado espontáneo. En este estudio, basándonos en un corpus paralelo, se ha investigado el grado de mitigación que se registra en las versiones meta italianas y españolas de cinco películas originales estadounidenses y se ha cotejado la frecuencia por minuto de palabrotas moderadas, fuertemente ofensivas y altamente ofensivas en dichos productos. De los datos recabados se observa que la presencia de vulgarismos en las versiones meta españolas es superior en comparación con las italianas y, por tanto, en estas últimas ha imperado en mayor escala la tendencia a la atenuación. Estos resultados coinciden con el número de ocurrencias por minuto de términos y secuencias malsonantes que se han inventariado en un conjunto de filmes de producción propia italianos y españoles. Por consiguiente, se puede vislumbrar que en la cultura española existe una mayor propensión a la inserción del lenguaje soez en los textos fílmicos que en la italiana, en la cual se percibe una mayor reticencia. Asimismo, en ambas lenguas y culturas en la traducción para el doblaje de palabrotas se constata que predominan las estrategias de hibridación y de domesticación.

Palabras clave: doblaje; léxico malsonante; tendencias traductivas; lengua-cultura italiana y española 
Abstract. Taboo words and their translation: a comparison between the Italian and Spanish dubbing of Anglophone films

Swear words and expressions occur in social interaction and mostly perform an offensive function. In film, they convey emotional strength to dialogue and typify characters linguistically. In addition, they act as orality markers that contribute to creating natural and plausible audiovisual speech - and make it closer to spontaneous spoken language. By drawing on a parallel corpus of five North-American films and their dubbing translations, the present study investigates and contrasts the degree of mitigation in the Italian and Spanish target versions, while comparing these to the original Anglophone texts. The frequency per minute of moderately, strongly and very strongly offensive swear words and expressions are calculated. The analysis of the data reveals that the Spanish versions contain a higher number of vulgar expressions than the Italian translations, which are conversely more prone to mitigation. These results parallel those obtained in a previous study that used the same methodology to compare Italian and Spanish domestic productions. Both sets of findings hint at a possible greater propensity in the Spanish than in the Italian culture to resort to swear words and expressions in filmic texts. However, strategies of ibridisation and domestication can be seen to play a role in the dubbing translation of swearing in both linguacultures.

Keywords: dubbing; swear words and expressions; tendencies of translation; Italian and Spanish linguacultures

\author{
Sumario \\ 1. Introducción 5. Discusión: versiones dobladas y \\ 2. El lenguaje malsonante y la \\ traducción para el doblaje \\ 3. Preguntas de investigación y \\ metodología \\ versiones originales comparadas en las \\ dos culturas \\ 6. Conclusiones \\ Referencias bibliográficas \\ 4. Extrapolación y análisis de los \\ resultados
}

\title{
1. Introducción
}

Existe un amplio número de publicaciones que han abordado la traslación de las palabrotas entre una determinada combinación lingüística y cultural; dichas investigaciones han demostrado que en la traducción para el doblaje impera en mayor o menor medida la tendencia a reducir y a mitigar el léxico soez. Sin embargo, hasta la fecha no se ha llevado a cabo ningún estudio empírico que compare el doblaje a dos lenguas de destino de un mismo idioma original. Esta comparación es necesaria para poder evaluar de una forma sistemática las normas y las tendencias que gobiernan en el doblaje de dos lenguas-culturas diferentes, cuyas versiones meta provienen de los mismos productos originales. Si se contrastan las pautas de actuación seguidas en sendos doblajes, es factible averiguar las peculiaridades de cada sistema cultural y analizar uno comparándolo con el otro. 
La presente investigación tiene como objeto el análisis de un conjunto de películas anglófonas y sus versiones meta italianas y españolas, que posibilita confrontar las soluciones de traducción adoptadas en la traslación del léxico malsonante. Los resultados que se obtendrán permitirán observar las similitudes y las divergencias entre las dos culturas de llegada. Asimismo, posibilitarán verificar si las pautas de actuación que se han seguido en la traducción de los vulgarismos en ambas culturas coinciden con las normas que rigen la inserción del número de palabrotas en las películas de producción nacional de cada país.

Abordar el análisis del lenguaje soez y su traducción es una tarea compleja. Los vulgarismos son constituyentes lingüísticos que los hablantes usan en la interacción social y su significado es esencialmente pragmático, factor que origina que su valor no sea unívoco y que la evaluación del impacto emocional y del efecto ofensivo que generan pueda cambiar, de igual modo que puede variar su clasificación.

El léxico malsonante tradicionalmente se ha catalogado en tres grandes grupos: $a$ ) insultos; $b$ ) imprecaciones, y $c$ ) un híbrido entre ambos tipos, que puede ubicarse en una clase u otra según la intencionalidad del emisor, el mayor o menor tono agresivo o violento con el que se formulen y el perjuicio o daño que causen a la imagen o identidad del interlocutor o una tercera persona (Crespo 2007; Culpeper 2010; Pavesi y Formenelli 2019).

Puesto que el significado de los términos y expresiones soeces no es semántico, sino connotativo y emocional, este está subordinado a variantes como los contextos lingüísticos y paralingüísticos en los que se emplean, la relación entre los participantes, las identidades y entornos sociales de los hablantes y las normas sociales que imperan en una cultura (Allan y Burridge 2006; Jay y Janschewitz 2008; Dewaele 2010; Díaz 2012).

Esta subordinación contextual y pragmática ocasiona que los efectos que producen las palabrotas y el grado de transgresión y ofensa que provocan dependan, por una parte, como indica Díaz (2012: 76-77), «de las circunstancias concretas y de los factores personales y sociales que rodean la comunicación»; por otra, de cada cultura y sus convenciones lingüísticas (Jay y Janschewitz 2008). De todas formas, resulta complicado establecer el grado de aceptación que muestra una determinada cultura hacia el lenguaje malsonante, dado que el índice de transigencia es heterogéneo y la mayor o menor tolerancia puede variar según los subgrupos sociales y culturales a los que pertenezcan los hablantes y las situaciones comunicativas en los que se enuncien las palabras y secuencias soeces (Haverkate 1994; Kerbrat-Orecchioni 2004; Zimmermann 1995).

La supeditación de su significado a las variables socioculturales y pragmáticas citadas origina que los vulgarismos, expresiones malsonantes y transgresivas, no siempre sean disfemismos, término con el que se cataloga el comportamiento descortés, ofensivo e inadecuado. Es decir, los vulgarismos, cuando se usan en las situacionales comunicativas y sociales apropiadas, no tienen que resultar per se disfemísticos (Crespo 2007; Jay y Janschewitz 2008). De hecho, las palabrotas en la interacción social conservan su efecto emotivo, que es consustancial, pero, como señala Christie (2013), su impacto ofensivo no es inherente, sino que está 
vinculado a como se evalúe dentro de los múltiples contextos sociales específicos, los cuales resultan esenciales para interpretar sus significados sociopragmáticos. A este respecto, se ha demostrado que el empleo de términos y expresiones soeces en determinadas situaciones comunicativas puede tener un afecto positivo y funcionar como marcadores de solidaridad en una comunidad concreta (Leech 1983; Daly et al. 2004; Culpeper et al. 2017).

\section{El lenguaje malsonante y la traducción para el doblaje}

Tradicionalmente se ha afirmado que en los productos doblados no se reproduce el mismo nivel de ofensa y transgresión que en los textos originales porque la presencia de léxico soez que se registra en las versiones meta suele ser más reducido en comparación con las películas originales. En investigaciones anteriores se ha demostrado que históricamente en el proceso de doblaje de filmes y series televisivas gobierna la tendencia a la atenuación (Toury 1995: 58-61). Dicha tendencia ha sido constatada por Goris (1993) del inglés al francés; por Pavesi y Malinverno (2000), Pavesi (2005), Bucaria (2009), Ledvinka (2010), Zanotti (2012), Formentelli y Monti (2014), Parini (2014), Beseghi (2016) y Giampieri (2017a, 2017b, 2018a y 2018b) del inglés al italiano; por Martí Ferriol (2005 y 2007), Soler Pardo (2012 y 2014), Fuentes-Luque (2015) del inglés al español; por De Laurentiis y Romero (2016) del español al italiano y por Zamora (2015) del italiano al español.

Esta pauta de actuación puede deberse a diferentes causas interrelacionadas, que van desde las directrices que imponen las empresas de distribución de productos audiovisuales doblados, pasando por las convenciones de doblaje que rigen en cada país hasta los problemas que genera la traslación de esta clase de términos y secuencias. Las distribuidoras suelen imponer unas directrices, y a este respecto Zanotti (2012: 366-377) señala que las estrategias de marketing deciden el nivel de censura y el grado de manipulación de un filme doblado, el cual depende esencialmente de factores puramente mercantiles: el objetivo es elaborar productos que garanticen el éxito comercial. Este condicionante ocasiona que los traductores habitualmente se decanten por soluciones que se amolden a la cultura meta y eviten el rechazo del producto por parte de los espectadores del país receptor.

El traductor y el resto de los agentes que participan en el doblaje, que son conscientes que el público cinematográfico es amplio y variado, procuran omitir formas socialmente malsonantes y groseras. Santaemilia (2008: 222-226) afirma, acerca de la traducción literaria, que se percibe una fuerte tendencia a la autocensura voluntaria y los traductores, deliberada o instintivamente, producen textos que sean aceptables desde una óptica social. El mismo autor señala que el traductor tiende a hacer más formal y neutro el texto meta respecto al original, activando una especie de estrategia generalizada de hipercorrección. Ranzato (2010: 66) indica que el tono más bajo y menos ofensivo que se constata en el doblaje se debe a la búsqueda del confort factor por parte de los traductores, que intentan cumplir con las expectativas de la empresa distribuidora y del público receptor; 
en el caso del léxico malsonante y obsceno, la censura o autocensura evita la excesiva transgresión y permite disminuir el impacto ofensivo en la recepción. Por su parte, Parini (2013: 160) añade que los traductores intuyen que no deben superar un determinado umbral, pero dicho umbral depende de las apreciaciones personales y subjetivas de los propios traductores y del resto de los agentes que intervienen en el doblaje.

Vinculadas con estos aspectos, están las convenciones de doblaje que imperan en cada cultura, las cuales dependen de la legislación vigente de cada país, del tipo de destinatario (Zanotti 2012: 355-356) y del gusto del público de esa cultura (Ranzato 2009: 46). La catalogación de filmes, según los contenidos de la trama y la edad de los espectadores, puede influir en la toma de decisiones del traductor. De hecho, Giampieri (2018a: 180) demuestra que el mayor o menor grado de mitigación del término malsonante anglófono motherfucker en su traslación al italiano depende esencialmente del tipo de audiencia En los filmes destinados a un público adolescente, menores de 18 años, la omisión es mayor que en los largometrajes dirigidos a una audiencia más adulta, cuyo porcentaje de supresión es más reducido.

Asimismo, la traslación de palabrotas de un sistema lingüístico y cultural a otro resulta una labor ardua por motivos estrictamente lingüísticos. Los múltiples valores pragmáticos que poseen un amplio número de vulgarismos de la lengua de partida dificultan, al menos en parte, su traducción; así, por ejemplo, el término inglés fucking, por su polifuncionalidad sintáctica y pragmática, no corresponde a una única expresión en italiano (Pavesi y Malinverno 2000: 83-88). La falta del equivalente en dos pares de lenguas supone a su vez un obstáculo, y es el caso de las unidades fraseológicas que por lo general ofrecen una fuerte resistencia a la traducción (Richard 2008); este escollo traductológico se incrementa cuando se trata de fraseologismos vulgarizados, cuya carga ofensiva genera que aumente el número de omisiones en las versiones meta en comparación con otras clases de léxico malsonante (Ferrario 2015; Zamora 2015). De igual manera, entorpece la traslación el hecho de que un determinado término soez de la lengua origen y su homólogo formal y pragmático en la lengua de llegada puedan presentar una frecuencia de uso distinta y un grado de transgresión diferente en una combinación linguística concreta. Estos factores ocasionan que en la traducción para el doblaje del lenguaje malsonante se observe en ocasiones una cierta desubicación textual y pragmática y una falta de naturalidad que originan interferencias y calcos, como demuestran Pavesi y Malinverno (2000: 82-83) y Formentelli y Monti (2014: 175) respecto al doblaje inglés-italiano y Fernández (2006) por lo que concierne al inglés-español.

Igualmente, existen otros elementos que pueden influir en la mayor o menor propensión a mitigar las películas de producción ajena: el grado de ofensa que causan los distintos vulgarismos presentes en los filmes originales y el tipo de personaje y los contextos en los que desenvuelve la escena.

Respecto al primero, en el proceso de doblaje de términos y expresiones altamente soeces, por ejemplo las blasfemias, puede ser que el grado de conservación sea inferior en comparación con otras palabrotas cuya carga ofensiva sea más 
reducida e inocua. Esta hipótesis ha sido verificada por Giampieri (2018b) en el doblaje de filmes estadounidenses doblados al italiano. Por lo que concierne al segundo, la proporción de preservación del léxico malsonante presente en los diálogos enunciados por personajes marcados, es decir propensos a la violencia verbal, en situaciones comunicativas de máxima polémica es posible que sea mayor respecto a escenas en las que figuren personajes menos proclives al empleo del lenguaje soez y se expresen en situaciones menos conflictivas. Esta suposición ha sido constatada por Formentelli y Monti (2014: 190) para el doblaje y por Baines (2015: 438-439) para la subtitulación.

\section{Preguntas de investigación y metodología}

En la presente investigación nos basamos en un corpus trilingüe paralelo, elaborado para comparar las tendencias generales que imperan en la traducción para el doblaje del lenguaje malsonante en las culturas italiana y española.

El análisis se fundamenta en el visionado y cotejo de películas originales estadounidenses contemporáneas y sus correspondientes versiones meta en italiano y en español. El estudio tiene como objetivo primordial calibrar y comparar el grado de mitigación del léxico soez en los textos de llegada italianos y españoles. Relacionado con este propósito, se analiza asimismo, por una parte, si la mayor o menor atenuación que se constata en las versiones meta de ambas culturas coincide con la mayor o menor inserción de palabrotas por minuto que se verifica en los filmes de producción propia italianos y españoles; por otra, en qué medida las peculiaridades de la lengua del cine nacional de ambas culturas respecto al tratamiento del lenguaje malsonante repercuten en la recreación de los diálogos en las productos doblados de cada país. Las preguntas de investigación son las siguientes:

- ¿En las versiones dobladas italianas y españolas se registra el mismo grado de mitigación de los términos y secuencias malsonantes respecto a los filmes anglófonos originales?

- ¿La frecuencia por minuto del léxico soez que se constata en las películas italianas y españolas de producción ajena concuerda con el número de ocurrencias por minuto que se registra en los largometrajes italianos y españoles nacionales?

El corpus fílmico está formado por cinco películas estadounidenses y sus correspondientes versiones meta italianas y españolas (tabla 1). Los largometrajes, rodados en 2015 y 2016, pertenecen a géneros cinematográficos diferentes: un thriller -Black Mass-, dos dramas - The Big Short y Spotlight- y dos comedias - How to Be Single y Trainwreck-. La duración global de los filmes es de 608 minutos.

La selección de películas contemporáneas permite realizar una investigación que revele el panorama actual del doblaje de vulgarismos en el tercer milenio. Como se ha demostrado, las tendencias que gobiernan el doblaje del léxico mal- 
sonante han cambiado durante estos últimos decenios. En líneas generales, se puede afirmar que el porcentaje de mitigación de términos y expresiones soeces en las versiones meta italianas (Giampieri 2017b) y españolas (Soler Pardo 2015) ha ido decreciendo paulatinamente con el trascurso de los años; incluso, en el caso del doblaje al español, en algunos productos se aprecia una mayor vulgarización de las versiones meta en comparación con los filmes originales foráneos (Valdeón 2020).

Tabla 1. Corpus de películas anglófonas y las versiones dobladas en italiano y español

\begin{tabular}{|c|c|c|c|c|}
\hline $\begin{array}{l}\text { Título } \\
\text { original }\end{array}$ & $\begin{array}{l}\text { Año de } \\
\text { estreno }\end{array}$ & Director & Título en italiano & Título en español \\
\hline Black Mass & 2015 & S. Cooper & $\begin{array}{l}\text { Black Mass. L'ultimo } \\
\text { gangster }\end{array}$ & $\begin{array}{l}\text { Black Mass: } \\
\text { Estrictamente criminal }\end{array}$ \\
\hline The Big Short & 2015 & A. MaKay & La grande scommessa & La gran apuesta \\
\hline Spotlight & 2016 & T. McCarthy & Il caso Spotlight & $\begin{array}{l}\text { Spotlight. Crímenes del } \\
\text { Vaticano }\end{array}$ \\
\hline Trainwreck & 2015 & J. Apatow & Un disastro di ragazza & Y de repente tú \\
\hline $\begin{array}{l}\text { How to Be } \\
\text { Single }\end{array}$ & 2016 & C. Ditter & Single ma non troppo & Mejor... solteras \\
\hline
\end{tabular}

McEnery (2006) ha propuesto una clasificación del léxico malsonante inglés, la cual ha sido adoptada por Valdeón (2020) para el español. Dicha clasificación incluye palabras y expresiones divididas en cinco categorías según el grado de ofensa que ocasionan - muy tenues, tenues, moderadas, fuertemente ofensivas y altamente ofensivas-. Sin embargo, las distinciones deben ser flexibles y su delimitación resulta compleja porque, como hemos señalado (apartado 1§), el uso y la interpretación de los vulgarismos están sujetos a multitud de variables sociopragmáticas.

Nosotros nos hemos decantado por una categorización más reducida y hemos incluido en nuestro análisis únicamente los términos y secuencias de perfil moderado, fuertemente y altamente ofensivo, sin hacer ninguna distinción entre ellos, excluyendo del estudio los términos muy tenues o tenues, es decir de baja intensidad, que resultan escasamente ofensivos y no se consideran términos tabú ni en italiano ni en español. Por ejemplo, expresiones como Oh God, Oddio en italiano, o Holy Virgin, Virgen Santa en español, parece que han perdido su connotación blasfema en las dos culturas latinas y resultan inocuas.

Se han empleado los mismos criterios para la selección del lenguaje malsonante en las dos lenguas y culturas de llegada. Para la extracción de los datos, se ha llevado a cabo un visionado detallado de cada filme original y sus dos versiones meta, que nos ha permitido registrar manualmente la totalidad de las ocurrencias del lenguaje malsonante presentes en los largometrajes fuente y en los filmes doblados.

En la siguiente tabla se indican las palabrotas más frecuentes que se han inventariado en los tres subcorpus, partiendo de fucklfucking; fuck, cuya traduc- 
ción sería cazzo, del cazzo, cazzo di, etc., en italiano y joder, puto-a, de mierda, mierda de, etc., en español, aunque esta puede variar según los distintos contextos. Asimismo, se señalan las traducciones pragmáticas más comunes y aproximadas al inglés de cada uno de los vulgarismos italianos y españoles, así como el número de ocurrencias.

Tabla 2. Número de ocurrencias de las siete palabrotas más frecuentes en los tres subcorpus

\begin{tabular}{lll}
\hline Filmes originales anglófonos & Versiones meta italianas & Versiones meta españolas \\
\hline Fuck / Fucking (380) & Cazzo/ cazzo dil del cazzo & Joder (Fuck / Fucking) (117) \\
Shit / Shitty / Shittily (132) & (Fuck / Fucking) (114) & Puto/a (104) (Fuck / \\
Motherfucker (16) & Merda / Merda di (Shit) & Fucking) \\
Asshole (12) & (41) & Mierda / Mierda de/ Esta \\
Prick (10) & Vaffanculo (Fuck off) (24) & mierda de (Shit) (53) \\
Damn (8) & Stronzo (Asshole) (20) & Coño (Fuck) (48) \\
Faggot (5) & Bastardo (Bastard) (15) & Cabrón (Bastard) (21) \\
& Coglione (Asshole) (14) & Capullo (Asshole) (15) \\
& Cazzata (Bullshit) (11) & iQué te jodan! (Fuck off') \\
& & (10) \\
\hline
\end{tabular}

Como se ha indicado previamente, los términos y secuencias soeces que se han inventariado en los tres subcorpus son moderadas, fuertemente y altamente ofensivas en las tres culturas. Por lo que concierne al italiano y al español, se han realizado dos sondeos paralelos previos para evaluar el grado de ofensa que provocan las palabrotas en los hablantes de sendas culturas y los resultados extraídos han permitido establecer una clasificación teniendo en cuenta su impacto ofensivo. ${ }^{1}$

En la tabla 3 se muestra el grado de ofensa que han manifestado los hablantes hacia cada uno de los vulgarismos presentes en los filmes de las dos culturas meta, siguiendo una escala gradual de intensidad. Como se puede observar, dichas palabrotas han suscitado un índice de ofensa medio y alto. Algunas palabras y secuencias malsonantes que figuran en la tabla 2 se pueden catalogar como moderadas, puesto que, de 0 -nada ofensiva - a 3 - muy ofensiva —, gravitan entre menos de 1 y 1,3; es el caso de las palabrotas italianas cazzo y merda y las

1. En los sondeos, que han sido cumplimentados a través de aplicación Encuestas.um.es, se les solicitaba a los participantes, divididos en dos grupos, uno de menores de veinticinco años y otro de entre veinticinco años y cincuenta y cinco, que manifestasen el índice de transgresión que les producía la recepción de una amplia gama de palabrotas. Los sujetos debían seleccionar una de las siguientes cuatro opciones: nada ofensiva, poco ofensiva, bastante ofensiva y muy ofensiva, cuantificadas numéricamente de 0 a 3 . La encuesta italiana ha sido cumplimentada por 229 sujetos de nacionalidad italiana: 111 menores de veinticinco años y 118 entre veinticinco y cincuenta y cinco años, en su totalidad alumnos y docentes de las Universidades de Parma, Milán, Forlì y Roma «Tor Vergata». El cuestionario español análogo ha sido cumplimentado por 304 participantes, íntegramente estudiantes y profesores de la Universidad de Murcia, cuya lengua materna es el castellano. De ellos, 196 son menores de veinticinco años y 108 tienen entre veinticinco y cincuenta y cinco años. 
españolas coño, joder, mierda y sus derivados. El resto de los vulgarismos de ambos idiomas sobrepasan el umbral del 1,5 y algunos superan el 2; por consiguiente, resultan bastante y/o fuertemente ofensivos tanto para los participantes de la encuesta menores de veinticinco años como para los sujetos entre veinticinco y cincuenta y cinco años, los cuales en las dos culturas han mostrado un menor grado de aceptación.

Tabla 3. Grado de ofensa, según las encuestas, de los siete vulgarismos italianos y españoles más frecuentes que se han inventariado en las versiones meta

\begin{tabular}{lcclcc}
\hline Italiano & \multicolumn{2}{c}{ Edad } & Español & \multicolumn{2}{c}{ Edad } \\
\hline Vulgarismos & $<25$ años & $>25$ años & Vulgarismos & $<25$ años & $>25$ años \\
\hline Bastardo & 1,55 & 2,07 & iQué te jodan! & 2,01 & 2,18 \\
\hline Coglione & 1,46 & 2,00 & Puto/a X & 1,91 & 1,95 \\
\hline Vaffanculo! & 1,46 & 1,97 & Cabrón & 1,64 & 1,88 \\
\hline X del cazzo & 1,04 & 1,26 & X de mierda & 1,31 & 1,33 \\
\hline X di merda & 0,88 & 1,24 & Capullo & 1,29 & 1,53 \\
Cazzo & 0,80 & 1,05 & Coño & 0,90 & 0,97 \\
\hline Merda & 0,66 & 1,01 & Mierda & 0,69 & 0,72 \\
Cazzata & 0,71 & 0,86 & Joder & 0,60 & 0,70 \\
\hline
\end{tabular}

En los siguientes ejemplos se muestran las tres estrategias principales de traducción que han gobernado en la traslación de los diálogos fílmicos anglófonos al italiano y al español: conservación, compensación y mitigación, sea mediante la omisión o a través de la sustitución por un término menos soez o eufemístico.

En el ejemplo (1), se puede observar que las dos traducciones en sendos idiomas reproducen el potencial ofensivo de los términos malsonantes presentes en el diálogo original e, incluso en el caso de una expresión inglesa, se agrava la fuerza soez de la misma en los dos idiomas de destino: What the hell?, en italiano se ha traducido con Ma che cazzo!, que correspondería a la secuencia inglesa What the fuck; en español, se han decantado por insertar iQué cojones!, cuyo equivalente anglófono es What the fuck. De forma inversa, la expresión Are you fucking kidding $m e$ ? ha sido mitigada en español mediante la inclusión de la unidad fraseológica neutra ¿!Me tomas el pelo!?

Ejemplo 1

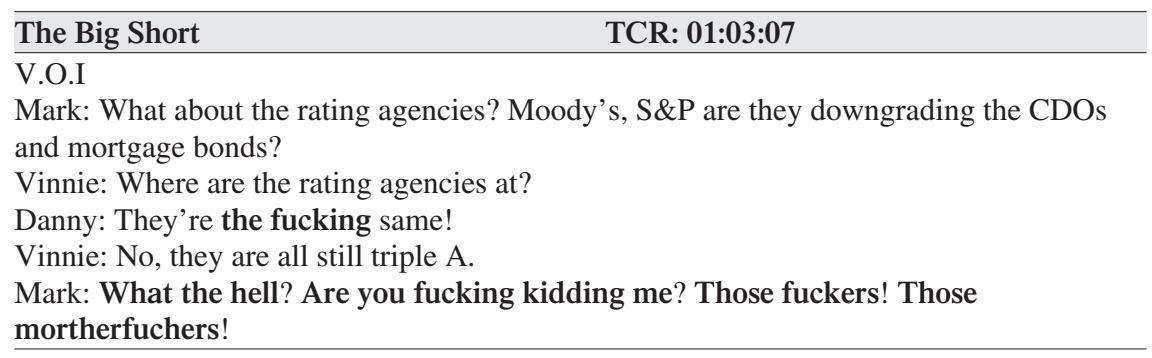


V.D.I

Mark: E le agenzie di rating? Moody's, S\&P stanno svalutando i CDO e le obbligazioni ipotecarie?

Vinnie: Che dicono le agenzie di rating?

Danny: Sempre la stessa cazzo di balla!

Vinnie: Ancora tutti tripla A.

Mark: Ma che cazzo! Mi stai prendendo per il culo!? Che bastardi! Sono dei pezzi di merda!

V.D.E

Mark: ¿Y las agencias de calificación? Moody’s, S\&P están bajando el rating a los CDOs y a los bonos hipotecarios?

Vinnie: ¿Las agencias de calificación?

Danny: Siguen igual ¡Qué mierda!

Vinnie: Siguen siendo triple A.

Mark: ¡Qué cojones! ¿!Me tomas el pelo!? ¡Son unos hijos de puta!

Por el contrario, en el ejemplo (2), se percibe que las estrategias que se han empleado en la traducción de las dos culturas difieren de forma considerable. Únicamente en la versión meta italiana se atenúa drásticamente la fuerza ofensiva del texto fuente, preservando solo uno de los tres términos malsonantes presentes en el diálogo original. En la versión española, por su parte, se recurren a soluciones que permiten conservar la misma intensidad ofensiva de las tres expresiones vulgares que figuran en el texto de partida.

Ejemplo 2

Black Mass TCR: 56:19

V.O.A

Brian Halloran: Bulger paid 20 grands to keep quite about that Listen, you gotta protect me. If you don't I'm fucking dead.

(...)

Brian Halloran: Look. I made my living on the streets, ok? Alright? I know these things.

Ehy, look, look at me. You gotta protect me.

John: Well so far you haven't given us anything to have protection.

Brian Halloran: Are you fucking deaf? I gave you two fucking names.

V.D.I

Brian Halloran: Bulger mi ha dato 20 mila dollari per non parlare dell'omicidio. Sentite, dovete proteggermi. Se non mi proteggete, sono morto.

(...)

Brian Halloran: Senti, io sono uno che vive nelle strade, ok? È chiaro? E so come vanno certe cose. Ehi, guardami, guardami. Voi dovete proteggermi.

John: Fino ad ora non ci hai dato assolutamentente niente per meritare la protezione.

Brian Halloran: Ma siete tutti sordi per caso!? Vi ho appena dato due cazzo di nomi. 


\section{V.D.S}

Brian Halloran: Bulger me dio 20 de los grandes para comprar mi silencio. Joder, tenéis que protegerme, si no estoy muerto.

(...)

Brian Halloran: A ver, me gano la vida en la calle, ¿vale? ¿Entiende? Estoy al tanto de todo. ¡Míreme! ¡Míreme! ¡Tienen que protegerme!

John: Hasta ahora no nos has dado nada para que merezcas que te protejamos.

Brian Halloran: ¿!Están sordos, joder!? Les he dado dos putos nombres.

\section{Extrapolación y análisis de los resultados}

\subsection{Doblaje}

En los ejemplos anteriores se han ilustrado las tendencias que han imperado en el doblaje de las películas que conforman el corpus. En el subcorpus de películas estadounidenses se han registrado 622 términos y expresiones malsonantes, cantidad que contrasta con las 354 y 545 que se han inventariado en las versiones meta italianas y españolas, respectivamente (tabla 4). Por consiguiente, en los filmes italianos doblados se constata una fuerte atenuación respecto a las películas originales y se ha insertado un $41,5 \%$ menos de vulgarismos respecto a los largometrajes fuente. Contrariamente, en el doblaje al español se ha mitigado en menor medida y se observa una reducción de tan solo el 12,55\% en comparación con los filmes originales (figura 1).

Figura 1. Porcentaje de reducción de vulgarismos en el doblaje italiano y español respecto a las versiones originales anglófonas

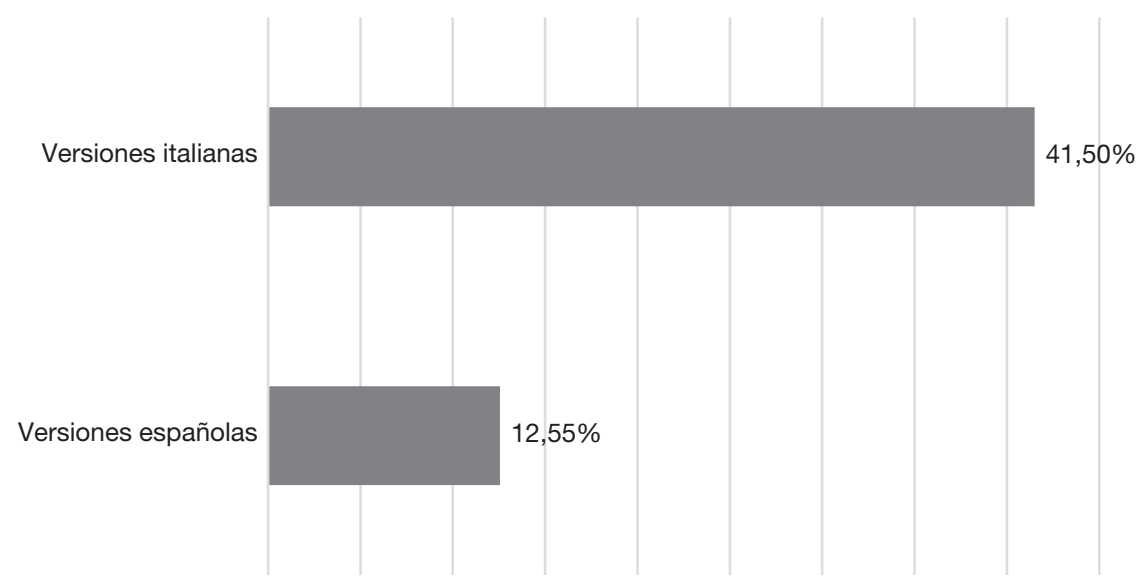

En las versiones meta españolas se ha inventariado un $28,95 \%$ más de lenguaje soez que en las versiones meta italianas. Este porcentaje superior se refleja en cada una de películas dobladas en las dos culturas. 
Tabla 4. Frecuencia de palabras y expresiones malsonantes en los tres subcorpus

\begin{tabular}{lcccccc}
\hline Película & \multicolumn{2}{c}{ Original } & \multicolumn{2}{c}{ Versiones italianas } & \multicolumn{2}{c}{ Versiones españolas } \\
\hline Black Mass & 295 & $100 \%$ & 145 & $49,15 \%$ & 240 & $81,35 \%$ \\
\hline The Big Short & 164 & $100 \%$ & 100 & $60,97 \%$ & 140 & $85,36 \%$ \\
\hline Spotling & 45 & $100 \%$ & 23 & $51,11 \%$ & 48 & $106,66 \%$ \\
\hline Trainwreck & 81 & $100 \%$ & 58 & $71,60 \%$ & 87 & $107,4 \%$ \\
How To Be Single & 37 & $100 \%$ & 28 & $75,67 \%$ & 34 & $91,89 \%$ \\
Total & 622 & $100 \%$ & 354 & $58,50 \%$ & 545 & $87,45 \%$ \\
\hline
\end{tabular}

A falta de estudios más exhaustivos que analicen una mayor cantidad de películas con el fin de tener a disposición una base de datos más amplia, los resultados recabados permiten vislumbrar la hipótesis según la cual los traductores italianos en las versiones meta tienden a disminuir el lenguaje malsonante y a rebajar el impacto ofensivo en mayor medida que los españoles. En dos de las cinco películas, los traductores españoles han intensificado la carga ofensiva de los filmes originales mediante la inserción de un número mayor de expresiones malsonantes. En las tres restantes, se aprecia que las diferencias entre los largometrajes anglófonos y sus versiones meta españolas son reducidas. Esta tendencia contrasta con las normas que han gobernado el doblaje al italiano; en las cinco versiones meta italianas se ha procurado mitigar el tono ofensivo y reducir la cantidad de palabrotas en un porcentaje elevado; en dos de ellas la pérdida alcanza el $50 \%$. Aunque las diferencias entre el doblaje italiano y el español no resulten significativas (estadísticamente presentan un p-valor de $0.788^{2}$ ), se percibe una disparidad entre las películas de producción ajena italianas y españolas. Dicha desigualdad se refleja en la frecuencia por minuto de palabrotas en las versiones meta de cada cultura: una cada minuto y 43 segundos en italiano y una cada minuto y seis segundos en español (tabla 5).

\subsection{Comparación entre las versiones meta y los productos nacionales}

Para completar nuestro estudio creemos que es necesario investigar si las tendencias divergentes que se han observado en el doblaje italiano y español respecto a la inserción del léxico malsonante se corroboran en las películas de producción propia de ambas culturas. En otras palabras, si el mayor grado de atenuación y la menor carga ofensiva que se han constatado en el doblaje italiano en comparación con el español se confirma también en la elaboración de los guiones de los filmes nacionales de los respectivos países. En caso de que se existiera un paralelismo entre ambos tipos de productos, original y meta, se podría deducir que los agentes de doblaje de las dos lenguas orientan sus traducciones a las normas que rigen en los diálogos de los largometrajes nacionales de cada país. Esta suposición se fundamenta en estudios anteriores, en concreto (Pavesi y Formentelli

2. El test ha sido realizado empleando ANOVA de una vía. Sección de Apoyo Estadístico. Área Científica y de Investigación. Universidad de Murcia. <www.um.es/web/acti>. 
2019: 576), los cuales han demostrado como el mayor o menor tono soez de las versiones meta suele estar a caballo entre los patrones adoptados en los filmes originales extranjeros que se doblan y los modelos que rigen las películas de producción propia del país de destino, siendo el resultado final un híbrido en el que influyen y confluyen las dos pautas de actuación. A este respecto, Baños (2014: 431) sostiene que el análisis de las producciones nacionales puede servir para averiguar las características específicas de la lengua de ficción —en el idioma de destino y ser un apoyo para el traductor a la hora de adoptar las estrategias más adecuadas para lograr que los diálogos fílmicos, domesticados, resulten verosímiles y naturales a la audiencia meta-.

Zamora (2020) ha realizado un estudio en el cual se compara la cantidad de vulgarismos que se registra en un grupo de películas italianas y españolas de producción propia, siguiendo los mismos criterios que se han aplicado para el análisis de los largometrajes estadounidenses que componen el corpus trilingüe paralelo del que nos hemos servido en este artículo. La investigación se basa en un corpus bilingüe comparable que está formado por diez filmes italianos y diez españoles que fueron rodados entre los años 2005 y 2015 y cuya duración temporal en su conjunto es similar en ambas culturas. Las películas pertenecen a diferentes géneros cinematográficos — dos thrillers, dos dramas y seis comedias-, los mismos que se han incluido en nuestro corpus, aunque el número de filmes es superior. El autor ha seguido un procedimiento idéntico al que se ha empleado en la presente investigación y el análisis se ha llevado a cabo seleccionado la misma tipología de léxico malsonante: palabras y secuencias moderadas, fuertemente y altamente ofensivas. Los resultados revelan que en los filmes nacionales españoles la presencia de palabras soeces por minuto es superior que en las películas originales italianas.

Tabla 5. Frecuencia de términos malsonantes por minuto en los largometrajes originales anglófonos, italianos y españoles y en las versiones meta italianas y españolas. (Los datos referidos de los filmes nacionales, Zamora 2020: 63-64.)

\begin{tabular}{lll}
\hline Cultura & Filmes doblados & Filmes originales \\
\hline Anglófona & & Uno cada $58^{\prime \prime}$ \\
\hline Italiana & Uno cada $1^{\prime \prime} 43^{\prime \prime}$ & Uno cada $1^{\prime \prime} 37^{\prime \prime}$ \\
\hline Española & Uno cada $1^{\prime} 06^{\prime \prime}$ & Uno cada $11^{\prime \prime} 05^{\prime \prime}$ \\
\hline
\end{tabular}

De media, las diez películas italianas nacionales seleccionadas contienen una palabrota cada minuto y 37 segundos, mientras que las diez películas españolas contienen una palabrota cada minuto y 5 segundos. Estos resultados confirman la tendencia que se ha verificado en el doblaje, según la cual en las películas españolas la inclusión de léxico soez es más elevada que en los productos italianos análogos. Dicha diferencia es muy superior y se incrementa notablemente en los filmes de producción propia pertenecientes al género comedia. En italiano, un vulgarismo cada dos minutos y 16 segundos; en español, uno cada 57 segundos (Zamora 2020: 63-64). 
A modo de resumen, los datos extraídos de los corpus formados por películas de producción propia y por filmes de producción ajena muestran que en las películas españolas, originales y dobladas, se constata una mayor permeabilidad a insertar en los diálogos fílmicos insultos, improperios e imprecaciones en comparación con los productos italianos, nacionales y meta. Es decir, según los datos extrapolados, los directores, guionistas y traductores españoles parecen que son más proclives a incluir un mayor número de términos y expresiones soeces que los italianos.

\section{Discusión: versiones dobladas y versiones originales comparadas en las dos culturas}

Los términos y secuencias soeces son unidades multifuncionales pragmáticas que expresan emociones y actitudes y marcar grupos y normas sociales (Dewaele 2004). Sin caer en el prescriptivismo, se puede apuntar que la mutilación del léxico malsonante en los textos de llegada influye negativamente en la calidad del producto. La eufemización repercute en la caracterización e identidad de los personajes - sincronía de personajes_- en el desarrollo de la trama, implica cambios de registros linguiísticos y resta verosimilitud y naturalidad a los diálogos fílmicos (Pavesi e Malinverno 2000: 83). Asimismo, el empleo de vulgarismos, aunque depende de las distintas culturas y los idiolectos particulares de los hablantes de cada país, suele ser frecuente en la interacción social, especialmente en situaciones contextuales de máxima polémica; por consiguiente, son marcas orales que contribuyen a recrear en los textos fílmicos la oralidad prefabricada (Chaume 2001: 78).

La traducción para el doblaje, entendida como vehículo de mediación y adaptación intercultural, no es uniforme en todas las culturas porque, como se ha indicado anteriormente (apartados $1 \S$ y $2 \S$ ), existe una serie de motivos socioculturales que influyen en las pautas de actuación que se siguen en los distintos países - posible censura o autocensura y búsqueda del efecto confort factor, el cual se basa en las supuestas expectativas de la audiencia meta- Otras causas son los procesos de hibridación entre las películas fuentes extranjeras y los filmes nacionales de la cultura de destino que confluyen en los doblajes (Pavesi y Formentelli 2019: 576) y los factores vinculados a la dificultad que conlleva la traducción de términos y secuencias pragmatizadas, como es el caso de las palabrotas.

En las dos culturas meta comparadas se percibe una cierta tendencia a mitigar el léxico malsonante en las versiones dobladas y dicha atenuación es inferior en los textos de llegada españoles. El diferente grado de eufemización que se ha constatado en las versiones meta de cada cultura coincide con los resultados obtenidos en otras investigaciones anteriores que han abordado las estrategias que han imperado en los doblajes de ambos países.

Por lo que concierne al subcorpus de películas dobladas al italiano, se observa que los datos extraídos (figura 1, tablas 4 y 5) concuerdan en líneas generales con los porcentajes de preservación que presentan tanto Ledvinka (2010), autora que indica que en las versiones meta italianas de seis películas originales estadouni- 
denses se ha conservado el $65 \%$ del lenguaje malsonante, como Formentelli y Monti (2014), según los cuales en las versiones meta italianas de un conjunto de filmes anglófonos originales se ha mantenido el $46 \%$ del léxico soez y de slang. Asimismo, las cifras coinciden con el estudio llevado a cabo por Giampieri (2017a: 71), que demuestra que en el doblaje del filme estadounidense Ted 2 (2015) se ha mantenido el $63 \%$ del lenguaje tabú. Por lo que respecta al doblaje de series estadounidenses al italiano, Bucaria (2009: 17) indica que se constata una fuerte tendencia mitigadora; de 12 series, en cuatro se llega a eliminar hasta un $89 \%$ del léxico malsonante, en seis la atenuación se sitúa entre el $50 \%$ y el $25 \%$ y en dos se suprime únicamente el $2 \%$.

Por lo que respecta al subcorpus de filmes doblados al español, la leve tendencia a la mitigación que se constata (figura 1, tablas 4 y 5) difiere parcialmente de las conclusiones de otras investigaciones previas sobre el argumento; de unas, porque afirman que el grado de atenuación es más alto; de otras, porque argumentan una tendencia a la disfemización.

Hay estudiosos que demuestran que el porcentaje de eufemización en las versiones meta españolas es elevado. Soler Pardo (2012 y 2014) indica que en la traslación de fuck y sus derivados en la película Reservoir Dogs (1992), se ha omitido el 43,15\%, y en Jackie Brown (1997) se ha eliminado el 43,75\%. Rodríguez-Medina (2015), por su parte, señala que en el doblaje al español de la estructura Fucking en tres películas estadounidenses contemporáneas, cuyas tramas reproducen el mundo del crimen, se ha suprimido el 39,56\%. González Quevedo (2019) apunta que en el doblaje de seis películas estadounidenses, estrenadas entre los años 2009 y 2015, la eufemización es muy superior a la disfemización. Contrariamente, hay investigadores que constatan una tendencia opuesta: la disfemización. Valdeón (2015: 380), en un estudio sobre el doblaje inglés-español de una serie televisiva anglosajona, prueba que en los textos meta españoles se verifica un incremento del número de palabrotas respecto a los textos fuente. En una investigación más reciente, el mismo autor (2020: 271), que analiza un corpus serial mucho más amplio, afirma que en el doblaje español de series anglófonas se tiende a vulgarizar las versiones originales: la sustitución de palabras y expresiones neutras por palabrotas registra un aumento del 53,14\% y la omisión y la moderación del tono soez suponen únicamente el 13,88\%.

Cabe señalar que las discordancias con algunos resultados de estudios anteriores pueden deberse a los diferentes enfoques adoptados respecto a la clase de léxico malsonante seleccionado para llevar a cabo el análisis de los datos, así como a la tipología textual de las producciones, productos fílmicos y seriales. A este respecto, es necesario precisar que algunos investigadores sostienen que el hablado simulado de las series de televisión se asemeja en mayor medida al hablado espontáneo que el hablado fílmico, el cual suele resultar menos verosímil y natural por varios motivos. En las series, la acción es más dinámica (Alfieri et al. 2010: 85), la alternancia de turnos de palabra es más veloz (Mapelli 2016: 119) y el componente verbal es superior y los diálogos más densos (Motta 2015: 962).

En una investigación reciente, Gualdo y Zamora (2019) comparan dos series españolas —Médico de familia (1995-1999) y Los Serrano (2003-2008) — y sus 
remakes italianos —Medico in famiglia (1998-2016) e I Cesaroni (2006-2014)—. Ambas pertenecen al género comedia familiar, fueron emitidas en prime time en los dos países y están destinadas a un público juvenil. Los autores, que seleccionaron ocho episodios por cada una de las series de ambos países, afirman que se percibe una fuerte diferencia respecto a la inserción del léxico malsonante entre Un médico en familia / Medico in famiglia y Los Serrano / I Cesaroni. En las primeras se registran 78 casos en la española y 23 en la italiana; en las segundas, 676 y 84, respectivamente. En el estudio se constata que el número de ocurrencias de términos y expresiones soeces global presentes en las series españolas, 754, es muy superior al que se ha inventariado en los productos italianos, 107. Por lo que concierne a la frecuencia de uso por minuto, las divergencias son sustanciales entre ambas culturas; una palabrota cada minuto y seis segundos en las series españolas, una cada siete minutos y dos segundos en las italianas.

A diferencia de las series españolas, una buena cantidad de productos seriales italianos sigue cumpliendo una función didáctica modellizzante o rimodellante, es decir, a través de las series se muestra a los espectadores la forma en la que pueden o deben expresarse según el rol o estatus social y la situación comunicativa (Alfieri 2012: 58-61). Por consiguiente, se elaboran diálogos moderadamente controlados en todos los planos lingüísticos, incluido el léxico-semántico, nivel en el que se inserta el léxico malsonante.

La tendencia a un menor uso del lenguaje soez que se constata en las series italianas respecto a las españolas coincide con el número inferior de vulgarismos que se registra en los filmes nacionales y doblados italianos en relación con los españoles. En otras palabras, sea en las series o en las películas nacionales como en las versiones meta, se aprecia en los productos italianos una menor propensión a insertar palabrotas en comparación con las producciones españolas.

De hecho, se puede avanzar la hipótesis según la cual es probable que exista una correlación entre la frecuencia de uso del lenguaje soez en las películas italianas nacionales y dobladas, por un lado, y la frecuencia de uso del léxico malsonante en los largometrajes españoles originales y meta, por otro. En los filmes italianos de producción propia se registra una palabrota cada minuto y 37 segundos y en las películas de producción ajena, una cada minuto y 43 segundos. En los productos españoles, nacionales y meta, la cantidad de términos malsonantes que se han inventariado por minuto es superior: uno cada minuto y 5 segundos y uno cada minuto y 6 segundos, respectivamente (tabla 5).

Dicho paralelismo parece que deja entrever que las versiones meta de cada cultura se sitúan a mitad de camino entre la lengua empleada en los largometrajes originales foráneos y la lengua de las películas nacionales de la cultura de destino, siendo el doblaje el resultado del proceso de hibridación de ambos tipos de productos (Pavesi y Formentelli 2019: 576). Los datos extraídos de nuestro corpus trilingüe paralelo y del corpus comparable de Zamora (2020) demuestran que los filmes originales anglófonos presentan la frecuencia de palabrotas por minuto más elevada — una cada 58 segundos —, le siguen, como hemos anteriormente indicado, los largometrajes españoles — una cada minuto y 5 segundosy las películas italianas —una cada minuto y 37 segundos- (tabla 5). Estos 
resultados ratifican dicha hibridación y constatan que en ambas culturas el doblaje gravita sobre la oralidad simulada de las producciones nacionales. Esta confluencia origina que en el doblaje italiano se observe una cierta tendencia a domesticar el texto original foráneo sobre la base de la lengua del cine de las películas de producción propia (Pavesi 2013), tendencia que, en vista de los datos extraídos en esta investigación y en Zamora (2020), impera asimismo en el doblaje español.

\section{Conclusiones}

A falta de otros estudios que hayan confrontado la traslación del lenguaje malsonante en versiones meta de culturas diferentes partiendo de la misma lengua origen, los datos recopilados y analizados constatan que en el doblaje italiano se percibe una mayor tendencia a mitigar el léxico soez y atenuar el tono ofensivo y vulgar presente en los largometrajes originales extranjeros que en el doblaje español. Los resultados indicados por otros expertos, que han abordado las normas que gobiernan la traducción de palabrotas en los dos países por separado, refrendan dicha afirmación. En concreto, estudios como el realizado por Valdeón (2020) demuestran que en las versiones meta españolas existe una inclinación a vulgarizar los textos de destino.

Asimismo, esta investigación y el estudio que compara la inserción de vulgarismos en filmes originales españoles e italianos, muy superior en las películas españolas, inducen a afirmar que la cultura española es más permeable al uso del léxico malsonante en los diálogos fílmicos que la italiana, que es más reacia.

De hecho, la similitud respecto a la frecuencia por minuto de palabrotas que se constata entre los productos de producción propia y ajena italianos, por un lado, y los filmes nacionales y doblados españoles, por otro, confirman que en los doblajes, como indican Pavesi e Formentelli (2019: 576), tiene lugar un proceso de hibridación, siendo la versión meta una combinación entre la lengua del texto origen y la lengua de la producción nacional de una determinada cultura. Por consiguiente, en el caso del doblaje italiano y español de películas anglófonas se observa una cierta inclinación por parte de los traductores a aplicar la estrategia de la domesticación del filme original de destino. En las producciones nacionales italianas el número de léxico malsonante por minuto es relativamente bajo; por tanto, en las versiones meta italianas se reduce la cantidad de vulgarismos presentes en los filmes originales extranjeros. En las películas nacionales españolas se registra una cantidad de lenguaje soez elevada; en consecuencia, en los productos doblados se conserva una proporción alta e incluso se incrementa su cuantía en comparación con los filmes originales estadounidenses.

Somos conscientes de que la cantidad de filmes que componen el corpus es reducida y que es preciso para futuras investigaciones ampliar considerablemente el número de películas que conforman el corpus con la finalidad de incrementar la fiabilidad de los resultados. Sin embargo, el presente estudio contrastivo puede considerarse una primera aproximación al análisis de las tendencias que rigen en la traducción para doblaje de palabrotas en las dos culturas. 
Igualmente, creemos que resulta necesario para completar nuestra investigación llevar a cabo un estudio con el fin de averiguar, por una parte, si la diferencia que se constata deriva del gusto y de las expectativas reales de la audiencia de las dos culturas; por otra, si el público receptor de los dos países manifiesta el mismo grado de aceptación hacia el léxico malsonante en las películas de producción propia que en las versiones dobladas.

\section{Referencias bibliográficas}

ALFIERI, Gabriella (2012). «La fiction tra italiano modello e modelli di italiano. Dal teleromanzo alla soap opera». En: GARgiulo, Marco (ed.). L'Italia e i mass media. Roma: Aracne, p. 51-76.

Alfieri, Gabriella; FirRincieli, Federica; Giuliano, Mariella; Iannizzotto, Stefania; MоттA, Daria (2010). «Il parlato oralizzato della fiction tra paleo- e neotv». En: Mauroni, Elisabetta; PiotTi, Mario (eds.). L'italiano televisivo 1976-2006. Florencia: Accademia della Crusca, p. 83-182.

Allan, Keith; Burridge, Kate (2006). Forbidden Words: Taboo and the Censoring of Language. Cambridge: Cambridge University Press.

BAINES, Roger (2015). «Subtitling Taboo Language: using the Cues of Register and Genre to Affect Audience Experience». Meta, 60 (3), p. 431-453.

Baños, Rocío (2014). «Orality Markers in Spanish Native and Dubbed Sitcoms: Pretended Spontaneity and Prefabricated Orality». Meta, 59 (2), p. 406-435.

Beseghi, Micòl (2016). «WTF! Taboo Language in TV Series: An Analysis of Professional and Amateur Translation». Altre Modernità: Rivista di studi letterari e cultural, 1, p. 215-231.

BuCARIA, Chiara (2009). «Translation and censorship on Italia tv: an inevitable love affair». Vial, 6, p. 13-32.

Chaume, Frederic (2001). «La pretendida oralidad de los textos audiovisuales y sus implicaciones en traducción». En: Agost, Rosa; Chaume, Frederic (eds.). La traducción en los medios audiovisuales. Castellón: Universitat Jaume I, p. 77-88.

Christie, Chris (2013). «The Relevance of Taboo Language: An Analysis of the Indexical Values of Swearwords». Journal of Pragmatics, 58, p. 152-169.

Crespo, Elicer (2007). El eufemismo y el disfemismo. Proceso de manipulación del tabú en el lenguaje literario inglés. Alicante: Servicio de Publicaciones de la Universidad de Alicante.

CULPEPER, Jonathan (2010). «Conventionalised impoliteness formulae». Journal of Pragmatics, 42 , p. 3232-3245.

CulPePer, Jonathan; Haugh, Michael; Sinkeviciute, Valeria (2017). «(Im)politeness and mixed messages». En: CulPEPER, Jonathan; Haugh, Michael; KadAr, Daniel (eds.). Palgrave handbook of (im)politeness. Basingstoke: Palgrave, p. 323-355.

Daly, Nicola; Holmes, Janet; Newton, Jonathan; StubBe, Maria (2004). «Expletives as solidarity signals in FTAs on the factory floor». Journal of Pragmatics, 36, p. 945-964.

De LaUrentiIs, Antonella; Romero, Lupe (2016). «Aspectos traductológicos en la traducción para el doblaje en Física o Química». En: Calvo, Cesario; SpInolo, Nicoletta (eds.). Translating orality. La traducción de la oralidad. MonTi, 3, p. 157-179.

Dewaele, Jean-Marc (2004). «The Emotional Force of Swearwords and Taboo Words in the Speech of Multilinguals». Journals of multilingual and multicultural development, 25, p. 204-222. 
- (2010). Emotions in Multiple Languages. Basingstoke: Palgrave Macmillan.

Díaz Pérez, Juan Carlos (2012). Pragmalingüística del disfemismo y la descortesía. Los actos de habla hostiles en los medios de comunicación virtual. Tesis Doctoral. Madrid: Universidad Carlos III. [en línea] <http:/hdl.handle.net/10016/15682> [Consulta: 12 abril 2020].

Fernández, María Jesús (2006). «Screen Translation. A Case Study. The Translation of Swearing in the Dubbing of the Film South Park into Spanish». Translation Journal, 10 (3) [en línea]. <http://translationjournal.net/journal/37swear.htm> [Consulta: 9 abril 2020].

FERRARIO, Laura (2015). «Da francamente me ne infischio a fottuto bastardo: le parolacce nell'italiano doppiato al cinema». [en línea] <http://www.treccani.it/magazine/lingua italiana/speciali/traduttese/Ferrario.htm> [Consulta: 12 abril 2020].

Formentelli, Maicol; Monti, Silvia (2014). «Translating slanguage in British and American films: a corpus-based analysis». En: PAvesi, Maria; Formentelli, Maicol; GHiA, Elisa (eds.). The languages of Dubbing. Fráncfort del Meno: Peter Lang, p. $168-195$.

Fuentes-Duque, Adrián (2015). «El lenguaje tabú en la traducción audiovisual: límites lingüísticos, culturales y sociales». Aesla 1. Centro Virtual Cervantes. [en línea] $<$ https://cvc.cervantes.es/lengua/eaesla/pdf/01/70.pdf > [Consulta: 14 marzo 2020].

Giampieri, Patrizia (2017a). «Taboo language and censorship in the Italian dubbing of Ted 2». Lingue e Culture dei Media, 2, p. 64-88.

- (2017b). «Are Dubbed Teen Films (Still) Censored?». Studies about Languages, 31, p. 52-69.

— (2018a). «(Mis)representations of Motherf** in Italian Film Dubbing». Altre Modernità: Rivista di studi letterari e culturali, 19, p. 175-189.

— (2018b). «Holy Gree: Blasphemies and Insults against religious figures in Italian film dubbing». Lingue e Culture dei Media, 2, p. 96-114.

GonZÁlez Quevedo, Marta (2019). «Una aproximación al eufemismo y al disfemismo en la Traducción Audiovisual». Revista de Lenguas para Fines Específicos, 25, p. 58-74.

GorIs, Olivier (1993). «The Question of French Dubbling: Towards a Frame for Sistematic investigation». Target, 5 (2), p. 169-190.

Gualdo, Riccardo; Zamora, Pablo (2019). «Italiano e spagnolo colloquiale a confronto: analisi di un corpus di fiction televisiva». Studi italiani di linguistica teorica e applicata, 3, p. 440-472.

Haverkate, Hern (1994). La cortesía verbal. Madrid: Gredos.

JAY, Timothy; JAnschewitz, Kristin (2008). «The pragmatic of swearing». Journal of Politeness Reasearch, 4, p. 267-288.

Kerbrat-Orecchioni, Catherine (2004). «¿Es universal la cortesía?». En: Bravo, Diana; Briz, Antonio (eds.). Pragmática socio-cultural: estudios sobre el discurso de cortesía en español. Barcelona: Ariel, p. 39-54.

LeDvinka, Fay (2010). What the fuck are you talking about? Traduzione, missione e censura nel doppiaggio en el sottotitolaggio in Italia. Turín: Eris.

LEECH, Geoffrey (1983). Principles of pragmatics. Londres: Longman.

Mapelli, Giovanna (2016). «Aspectos de la oralidad en las series televisivas españolas: los procedimientos de intensificación». Orillas, 5, p. 1-18.

Martí Ferriol, José Luis (2005). «Estudio descriptivo y comparativo de las normas de traducción en las versiones doblada y subtitulada al español del filme Monster's Ball». Puentes, 6, p. 45-52. 
- (2007). «An Empirical and Descriptive Study of the Translation Method of Dubbing and Subtitling». New Voices in Translation Studies, 3, p. 171-184.

MCENERy, Toni (2006). Swearing in English. Londres: Routledge.

MotтA, Daria (2015). «Diachronic Models of TV Dubbing on Contemporary Italian». Italica, 92, p. 951-970.

PARINI, Ilaria (2013). «Taboo and translation in audiovisual Works». En: BAYó, Susana; Ní Chuilleanáin, Eiléan; Ó Cuilleanáín, Cormac (eds.). Translation right or wrong. Dublín: Four Courts Press, p. 149-164.

- (2014). «I'm going to $\mathrm{F}^{* * * * *}$ kill you. Verbal censorship in Dubbing Mafia Movies». En: Iamartino, Giovanni; IAnNaccaro, Giuliana (eds.). Enforcing and eluding censorship. British and Anglo-Italian perspective. Newcastle: Cambridge Scholars Publishing, p. 144-166.

Pavesi, Maria (2013). «This and That in the Language of Film Dubbing: A Corpus-Based Analysis». Meta, 58 (1), p. 103-133.

Pavesi, Maria; Malinverno, Annalisa (2000). «Usi del turpiloquio nella traduzione fílmica». En: TAYLOR, Christopher (ed.). Tradurre il cinema. Trieste: Università degli Studi di Trieste, p. 75-90.

Pavesi, María; Formentelli, Maicol (2019). «Comparing insults across languages in films: Dubbing as cross-cultural mediation». Multilingua, 38 (5), p. 563-582.

Ranzato, Irene (2009). «Censorship or 'Creative' Translation?: The Italian Experience from Tennessee Williams to Woody Alenn to Six Feet Under». En: Federici, Federico (ed.). Translating Regionalides Voices in Audiovisuals. Roma: Aracne, p. 43-70.

- (2010). La traduzione audiovisiva. Analisi degli elementi culturospecifici. Roma: Bulzoni.

RichARD, Mabel (2008). «Las unidades fraseológicas y su resistencia a la traducción». Foro de profesores E/LE, 4, p. 1-10.

Rodríguez-Medina, María Jesús (2015). «Appraising the Translation of Dysphemisms. Insights into the Spanish Crime Film Dubbese». InTralinea 17. [en línea] <http:// www.intralinea.org/archive/article/appraising_the_translation_of_dysphemisms > [Consulta: 6 abril 2020].

Santaemilia, José (2008). «The Danger(s) of Self-censorship's: The translation of "Fuck" into Spanish and Catalan». En: Seruya, Teresa; Lin Moniz, María. Translation and Censorship in Different Times and Landcapes. Newcastle: Cambridge Scholars Publishing, p. 163-173.

Soler Pardo, Betlem (2012). «Translating and Dubbing Verbal Violence in Reservoir Dogs. Censorship in the Linguistic Transference of Quentin Tarantino's (swear) Words». The Journal of Specialised Translation, 20, p. 122-133.

- (2014). «Traducción y doblaje: análisis de fuck y su traducción al español de Jackie Brown». Entreculturas, 6, p. 127-139.

- (2015). On the Translation of Swearing into Spanish: Quentin Trarantino from Reservoir to Inglourious Basterds. Cambridge: Cambridge Scholars Publishing.

Toury, Gideon (1995). Translation Studies and Beyond. Ámsterdam: Filadelfia: John Bejamins.

VALDEón, Roberto (2015). «The (ab)use of taboo lexis in audiovisual translation: raising awareness of pragmatic variation in English-Spanish». Intercultural Pragmatics, 12 (39), p. 363-385.

- (2020). «Swearing and the vulgarization hypothesis in Spanish audiovisual translation». Journal of Pragmatics, 155, p. 261-272.

Zanotтi, Serenella (2012). «Censorship or Profit? The Manipulation of Dialogue in Dubbed Youth Films». Meta, 57 (2), p. 351-368. 
ZAmora, Pablo (2015). «Pautas de traducción de las unidades fraseológicas tabuizadas en el doblaje fílmico italiano-español». En: Domínguez, Fernando; Mogorrón, Pedro (eds.). Fraseología, Didáctica y Traducción. Fráncfort del Meno: Peter Lang, p. 321338.

- (2020). «La inserción del léxico malsonante en filmes originales italianos y españoles y su grado de aceptación en los dos sistemas culturales. Un estudio de caso». En: FoulQUIER, Ana; CARDUCCI, Laura. Traducción e Interpretación: entre investigación y didáctica. Fráncfort del Meno: Peter Lang, p. 57-71.

ZimmermanN, Klaus (2005). «Estudios de conversación entre jóvenes masculinos». En: Bravo, Diana (ed.). Estudios de la (des)cortesía en español. Categorías conceptuales y aplicaciones a corpora orales y escritos. Estocolmo: Buenos Aires: Dunken, p. 245272. 
